EPOS, XIV (1998), págs. 239-252

\title{
TEORÍA Y PRÁCTICA DEL GÉNERO EPISTOLAR EN FEDERICO GARCÍA LORCA
}

Genara Pulido Tirado

Universidad de Jaén

\section{RESUMEN}

En el presente trabajo se aborda la teoría del género epistolar en sus rasgos fundamentales, atendiendo a las características más destacadas que presenta a partir del siglo XVIII, momento en que nace la epísola privada en sentido moderno. Tal indagación teórica va acompañada del estudio de las cartas de García Lorca, las cuales constituyen un ejemplo magnífico de esta manifestación literaria, con toda la problemática crítica y teórico literaria que ello conlleva.

La epístola es una manifestación literaria —en el sentido primitivo derivado de lettera, es decir, escrita - antiquísima. Sin embargo, tal existencia a lo largo de los siglos no ha contribuido a definir y explicitar debidamente su sentido y función en las diferentes épocas históricas en las que ha tenido una mayor presencia. La epístola clásica, entendida tanto en su relación con la Biblia como en sus distintas manifestaciones de tipo literario y administrativo en el mundo grecolatino, ha sido objeto de un buen número de estudios críticos —V. el estudio fundamental de Suárez de la Torre, 1987. La historia de tan conflictiva forma literaria ha sido amplia y presenta abundante variedad for- 
mal, temática, funcional..., como ha puesto oportunamente de manifiesto L6pez Estrada (1960) en su valioso estudio. La epístola que aquí nos interesa es la moderna, la que surge a partir del siglo XVIII, a la par que la burguesía y el concepto de sujeto libre, pues es entonces cuando aparece la carta privada en tanto que manifestación de la privacidad de un sujeto que se comunica con otro, aunque tal privacidad se ha visto rota con frecuencia por la publicación de epistolarios que, en principio, no estaban destinados a un público amplio. También es cierto que en esta misma época se escriben cartas públicas que aparecen publicadas en distintos medios, por lo que aparecen totalmente desprendidas de su primitivo afán de privacidad. Hay que tener en cuenta, en cualquier caso, que en sus inicios muchos de los representantes de la nueva clase emergente sólo tienen acceso a la escritura a través de la carta, la cual se convierte así en un lugar privilegiado y único para manifestar y consolidar la nueva noción de sujeto. También es conocida de todos la existencia de la novela epistolar, forma literaria que, usando las estructuras fundamentales y básicas de la epístola, está caracterizada por su carácter ficticio, extenso, como corresponde a la novela, y público (V. Ch. E. Kany, 1937; Guillén, 1991).

Conviene recordar que el interés por la carta o la epístola se manifiesta fundamentalmente en la retórica, las artes dictaminis medievales oformularios son una buena muestra de ello a la vez que de su carácter normativo y alto grado de sistematización. En principio, por tanto, podemos decir que la carta interesa en tanto que manifestación comunicativa que pone en contacto a dos sujetos, uno de los cuales transmite unos contenidos a los que el segundo accede y puede contestar, por lo que la comunicación, en este caso, como en toda manifestación literaria, es una comunicación a distancia que difiere de la comunicación que se establece entre varios sujetos presentes que hablan y reciben respuestas en el acto, directamente.

La existencia de cartas literarias, por otro lado, puede llevarnos a cuestionar el carácter de esas otras cartas que, al menos en apariencia, no han sido escritas con propósito literario. Todo ello, en cualquier caso, no elimina el interés que ofrecen estas manifestaciones en el ámbito de los estudios literarios contemporáneos, sobre todo en una época en la que, tras una superproducción de estudios sobre el concepto mismo de lo literario, aún no podemos ofrecer una definición única, universalmente válida. Existen, además, otros factores a tener en cuenta. La carta o epístola forma parte de una amplia gama de manifestaciones escritas que se vienen englobando, por lo general, bajo el marbete de «escrituras del yo», «escritura subjetiva», etc., esto es, biografías, autobiografías, memorias, diarios..., en torno a las cuales existe en la actualidad un interés crítico muy destacado en el que, a nuestro juicio, debería incluirse la carta, la cual participa, durante todo el siglo XX que ya termina, del cultivo 
abundante de una peculiar forma de escritura subjetiva cuyo carácter literario, como en los demás casos citados, habrá como mínimo que discutir, previa determinación de lo que se considere hoy que es la literatura.

Es a partir de la Generación del 98 en España cuando las cartas - junto al ensayo (V. Concejo, 1981)-, sobre todo las de autores que han destacado en sus respectivas actividades literarias, han cobrado un gran interés por parte de la crítica. Ello se manifiesta, ante todo, en la recopilación y publicación de abundantes epistolarios. El profesor Gallego Morell (1986:211) ha notado este hecho:

A partir de las Cartas de Bécquer [Cartas literarias a una mujer aparecen publicadas y contienen la que es la mejor expresion de la poética de su autor], el género se dignifica y se prodiga.

La explicación que ofrece el citado profesor es la siguiente:

...el hecho de que la literatura española del siglo XX se comience a historiar bajo el metodo generacional, más o menos libremente aplicado, atrae el interés hacia el género epistolar que viene a ilustrar y a dar luz en torno a la obligada comunicación personal entre los hombres de una misma generación, aspecto que constituye uno de los ocho postulados de Petersen, plantilla obligada al ensayar una aplicación del método (ibidem).

El interés procede igualmente de un desmedido deseo de conocer la vida privada que, aunque con antecedentes (V. Ariès y Duby, 1990), está cobrando tintes patológicos en los últimos años, y la prensa llamada amarilla nos ofrece abundantes muestras de ello. Este interés por lo privado se traduce en el campo de las letras por el deseo de conocer a la persona de carne y hueso cuyas obras literarias se presentan como producciones de gran importancia que han hecho que determinados autores-personas pasen a formar parte de la cultura y la historia de toda una época. Si a esto unimos elementos concretos como homosexualidad, disputas, o amoríos varios, el interés crece enormemente.

En estos momentos, en los que la crítica biográfica no es ya lo que fuera a finales del siglo XIX y principios del XX, la vida de los escritores sigue interesando en tanto que puede ser un elemento, entre otros muchos, que contribuya a explicar su producción literaria. Las cartas, debido a la variedad señalada, pueden ofrecer valiosos elementos de interés crítico y teórico literario: el proceso de gestación de una obra, las variantes de poemas, ideas sobre el ser y la función de lo literario, esto es, poéticas, o las relaciones entre escritores y ar- 
tistas de una época que sirven para reconstruir el ambiente literario de aquélla, por poner algunos casos.

En cuanto a García Lorca, muchas son las cartas que escribió en sus treinta y ocho años de vida. La edición reciente del Epistolario completo [a partir de aquí E.C.] -aunque incompleto- de Andrew A. Anderson y Christopher Maurer constituye un documento valiosísimo que contiene, en sí mismo, como señalan los editores, su propia historia, pues hasta reunir las quinientas treinta y una cartas, postales y telegramas, muchos son los críticos que han investigado buscando y publicando materiales de este tipo desde 1955 (en que se plantea incluir cartas de Lorca en la segunda edición de sus Obras completas) hasta 1997.

Los editores son conscientes del valor del material que ofrecen:

.... un epistolario cuidadosamente editado supone un adelanto en el estudio de cualquier poeta. Permite hablar con mayor seguridad sobre su desarrollo poético o intelectual; trazar la accidentada historia de sus manuscritos; y captar las intenciones que abrigaba a la hora de ponerse a escribir (1997:7-8).

No es extraño, por tanto, que Ian Gibson, en su biografía de Lorca, haya tenido en cuenta estos doumentos, los cuales ocupan un lugar destacado en su obra, y menos cuando el investigador inglés señala, en primer término, la homosexualidad del escritor granadino y una visión global que resume así:

En esta biografía reivindico a un Lorca que, a pesar de ser «capaz de toda la alegría del mundo» (Aleixandre), pese a su carisma y múltiples dones, de todos reconocidos, conoce la depresión y sabe con sus huesos, como lo supo Oscar Wilde, lo que es ser tenido, tan injustamente, por repelente y nefasto. Reivindico a un Lorca generosamente comprometido con todos los que sufren, con los rechazados, los marginados, los perseguidos, los avergonzados, los que no encajan. Al Lorca revolucionario que en realidad fue. Al Lorca consciente de que iban a por êl (Gibson, 1998:11).

Para lograr tal fin las cartas ofrecen muchos más datos que los valiosos testimonios del hermano del poeta (V. Francisco García Lorca, 1980) y de otros muchos poetas e intelectuales que lo conocieron en vida. El valor literario, como el biográfico, es incuestionable porque no sólo se manifiesta en las cartas propiamente dichas, las cuales a veces se reducen a unas escuetas palabras en postales, sino porque esas cartas van acompañadas en muchos casos, además de por distintas disertaciones sobre el fenómeno poético, teatral o ar- 
tístico (producción, elaboración, difusión...), por fragmentos de obras literarias u obras literarias completas que el escritor envía al destinatario con la intención de recibir una crítica. Al igual que leía sus obras a sus amigos, García Lorca les enviaba obras para recibir su opinión. Así se explica que algunas de ellas tardaran mucho en publicarse y que otras, finalmente, no vieran nunca la luz pública. Esto le ha valido la calificación del «más grande juglar de la literatura española contemporánea» por parte de Gallego Morell (1986:208) ya que, como los antiguos juglares, durante una época de su vida estuvo más interesado en dar a conocer sus obras a sus amigos - ya fuera de forma oral o escrita- que en publicarlas.

Pero a Gallego Morell no se le escapan otros valores de las cartas lorquianas: la visión que nos ofrecen del poeta como hombre humano, sensible, rico en facultades, bueno en el sentido machadiano, entusiasta, pletórico de ilusiones y proyectos — «Lorca era lo reflejaban sus cartas» (ibidem: 208), juicio que no comparte Anderson, E.C.: 407-; la importancia para reconstruir el ambiente literario de la Generación del 98; y su carácter literario:

...las cartas de Lorca están transidas de literatura. Es cierto que no están escritas, como las de Bécquer, pensando en su publicación. Pero también hemos dicho que casi toda su producción poética no fue escrita tampoco pensando en su publicación. La lírica comenzó siendo para Lorca un lenguaje, una forma de comunicación, una necesidad de vivir: cabalmente lo que representa el género epistolar (ibidem: 212).

Y es que aclarar el carácter literario o no literario de determinadas cartas es necesario por cuanto las cartas privadas han sido situadas, con frecuencia, al margen de la literatura, como señala Pagés-Rangel (1997:6):

...estas cartas [privadas] han sido tradicionalmente excluidas del parnaso de los géneros literarios «mayores», de la dignidad del valor estético que éstos ostentan y de la autonomía que ellos reclaman para sí. Acostumbrada a modelos de lectura que privilegian textos y géneros claramente demarcados como «creativos» o «de ficción», la crítica literaria ha preferido no adentrarse demasiado en un territorio textual que dificulta e incluso pone en cuestionamiento las premisas básicas sobre las que se instala su análisis e interpretación. Así, en el árbol de la genealogía de la literatura, la carta privada ha compartido junto con la autobiografía, la memoria y el diario un destino y un espacio temporal: como sus parientes cercanos, ha sido, hasta muy recientemente, un sub-género, una especie secundaria, un miembro de una familia hegemónica. 
La misma Roxanna Pagés señala la asociación que se establecía en los siglos XVIII y XIX entre la carta y la comunicación oral, lo que equivalía a dar una ilusión de no-ficcionalidad. Patricia Violi (1987: 87-88) entiende los epistolarios como formas específicas dentro de una tipología más amplia de la interacción.

En término similares se manifiesta Roca Sierra (1990: 333), tras estudiar los elementos característicos de la epístola:

Nos encontramos, pues, ante un género sintético, fronterizo, bifronte: conjunción de dos tiempos diferentes, vínculo de dos espacios distantes, confluencia de lo puramente enunciativo con la constente referencia metatextual, límite entre la interacción dialógica y el discurso autónomo, máxima expresión, en suma, de la utilización retórica al servicio de la comunicación entre los hombres.

O Suárez de la Torre (1987: 177):

La carta es ante todo un instrumento de comunicación humana.

Y, efectivamente, aunque podamos discutir sobre el carácter literario de las cartas, lo que es incuestionable es que constituyen una forma de comunicación con características propias, con la existencia de un emisor, un mensaje y un destinatario, forma de comunicación de carácter dialógico que entronca con la conversación pero que, a su vez, difiere de ella en tanto que lo que presenta es un «diálogo diferido, un diálogo que tiene lugar en ausencia de uno de los dos interlocutores» (Violi, ibidem: 89). El emisor y el interlocutor son, a su vez, narrador y narratario de un discurso que, aunque privado, puede publicarse, como en el caso que nos ocupa, lo que conlleva una tarea editorial nada fácil que suelen compartir buena parte de los epistolarios que son fruto de larecogida de cartas privadas que no fueron escritas para tal fin.

Anderson y Maurer son conscientes de la responsabilidad de su labor, de ahí que indiquen tanto las fuentes de sus cartas como los criterios seguidos para su edición: modificación de la ortografía, acentuación y puntuación según las normas académicas actuales, excepto en los textos literarios, investigación en la fecha de escritura, anotaciones en las que se da cuenta de datos referidos a las personas y obras citadas o aludidas, relaciones literarias, datos bio-bibliográficos de emisor y destinatarios...

En términos generales, podemos decir que las cartas de García Lorca se ajustan al género tal como se practicaba en su época. Todos conocemos, por 
ejemplo, las cartas familiares de emigrados, hijos en el Servicio Militar o las escritas a raíz de algún viaje. Aquí, la ausencia y la distancia son los condicionamientos primeros de la práctica epistolar. Pero en el siglo XX, y a pesar de que no dejen de existir manuales sobre Cómo se escribe una carta -más centrados en cartas oficiales, de carácter administrativo o marcadas por algunos rasgos peculiares del destinatario, que en cartas personales, privadas-, esta práctica, tras el conocido enfrentamiento con la retórica normativa y la preceptiva decimonónica que empieza a producirse en el siglo XIX, goza de una gran libertad. La dificultad de fijar normas se manifiesta ya en un manual de 1878:

Comprendiendo el estilo epistolar, desde los conceptos más elevados hasta los más frecuentes en el trato íntimo y seno de la confianza, no puede sujetarse a una parte fija y determinada; la persona que dirige el escrito, la que lo recibe, la naturaleza del asunto, los variados accidentes de la forma, y sobre todo las múltiples circunstancias de la vida, son otros tantos obstáculos que se oponen a compendiar, en breves páginas, las leyes que lo rigen (apud Pagés-Rangel, ibidem: 12 ).

El epistolario de García Lorca se inscribe, en su mayor parte, dentro de la carta privada y, por tanto, no fue escrito para su publicación. En este sentido, el conocimiento de todas las respuestas que recibieron las cartas en su día constituye una labor esencial, pues sin él no se accede cabalmente al circuito completo de la comunicación. A pesar de esta carencia, que no es general, pues se conocen muchas cartas de respuesta, se puede afirmar que García Lorca no se planteó la posibilidad de que se hicieran públicas sus cartas, de lo que sí avisa al destinatario en algunas de ellas es de que no comente alguna cuestión sobre la que escribe, generalmente proyectos literarios, porque no tiene la seguridad de que lleguen a realizarse.

Pero la idea y el hecho de hacer públicas las cartas del gran poeta surgi6 pronto en sus destinatarios, en primer término porque demostraban la conexión existente con un escritor rodeado desde muy pronto de una aureola de malditismo y misterio que lo hacía muy atractivo.

La lectura pública de los destinatarios fue, sin duda, el primer paso. Jorge Guillén lo pone de manifiesto en una carta del 20-V-50 conservada en la Fundación García Lorca:

Claro que esos documentos de verdad tan comunicativa no sólo causan admiración y encanto. Sobre todo conmueven, nos conmueven de veras. He leído esas cartas a algunos amigos (apud E.C.: 11). 
Pero con anterioridad ya algún destinatario había manifestado su no intención de dar a conocer las cartas privadas del poeta, lo que presupone, por supuesto, que se lo había planteado previamente. Es el caso de Jorge Zalamea, a quien García Lorca escribe en 1927 contándole sus pesares (amorosos en gran medida, se entiende), a lo que el amigo contesta y afirma:

Te quiero y me quiero demasiado para jugar a los manuscritos famosos (apud Gibson, ibidem: 324).

Era el momento en que Lorca sufría por el amor y desamor de Emilio Aladrén. Su respuesta es desolada:

$\mathrm{Y}$ teniendo conflictos de sentimientos muy graves y estando transido de amor, de suciedad, de cosas feas, tengo y sigo mi norma de alegría a toda costa. [...]

Te hablo de estas cosas, porque tú me lo pides; yo no hablaría más que de lo que, exterior a mí, me hiere de lejos de una manera segura y sapientísima (E.C.: 581-82).

La intimidad descubierta por la petición del amigo y el problema de la interpretación para el lector intruso; problema de interpretación que en estas cartas apuntan, fundamentalmente, en dos direcciones:

1. estado anímico del poéta, ya se trate de su predisposición para la creación, de las relaciones con su familia y amigos, el derivado de su homosexualidad, con el morbo que ello ha despertado a lo largo de décadas, etc.;

2. ' la creación literaria en general, que se presenta en el envío de obras literarias, largas disertaciones sobre la creación poética, transmisión de proyectos, ambiente literario de la época y posición del autor en él, etc.

Ajeno sin duda a esta transmisión de su intimidad, el escritor, que tras luchar por el triunfo se siente acosado por la fama misma, la cual va en aumento a partir de 1928 , señala en una carta a su familia que las cartas no deben enseñarlas a nadie, pues tratan de cosas privadas. Lo hace en la carta escrita en Nueva York en agosto de 1929 (E.C.: 638):

Mis cartas creo que las debéis de leer vosotros y nada más, es decir, la familia, pero no les deis publicidad a nadie, porque son íntimas, son para vosotros y para nadie más, y además no tienen interés literario sino familiar, y otra cosa sería ridícula. 
La posición de García Lorca (V. Anderson en E.C.: 402, otros testimonios en este sentido) es contundente. Difícilmente podía imaginar que esa intimidad se viera violada y que sus más recónditos deseos y preocupaciones pudieran ser objeto de lectura y conocimiento por parte de cualquier persona que lo deseara. Y es que, como ha señalado Pagés-Rangel (ibidem: 13):

...podría decirse que la carta privada dramatiza como ninguna otra forma de escritura el conflicto del autor con respecto al poder sobre su obra y a la comparecencia del lector.

En cualquier caso, el poeta y dramaturgo no ha podido vivir para aprobar o, por el contrario, prohibir la publicación de este material. Las cartas están ahí y contienen un estilo propio del que intentaré dar cuenta, aunque sea en líneas generales. Las cartas privadas de Lorca, en contradicción con su carácter personal, aparecen sin el lugar y fecha de escritura -elementos fundamentales de la epístola, junto al que saluda, desde su aparición-, los cuales han tenido que reconstruir los editores por el contenido, del que siempre se pueden extraer datos de las actividades y proyectos del poeta que las sitúan, la mayor parte de las veces, con bastante fiabilidad. Además de los datos que los editores encuentran en el discurso están los extratextuales como sellos o matasellos. Por tanto, la localización espacio-temporal del espistolario está fijada y es importante en tanto que condiciona el contenido de las mismas: una pequeña excursión determinará el envío de una postal o la reflexión sobre un paisaje o un conjunto histórico desconocido hasta entonces, una larga estancia en otro país o en Madrid, por el contrario, dará lugar a cartas largas en las que el autor cuenta cuál es su estado de salud, su actividad literaria, sus relaciones con los amigos...

El hecho de que el narratario epistolar aluda a una o pocas personas empíricas, frente a la complejidad y variedad que puede presentar en discursos literarios clásicos como la novela, ayuda al lector, y por supuesto a los editores, a ubicar las cartas en un espacio, un tiempo y una situación determinados. El destinatario, en cualquier caso, desde el momento en que se nos presenta a través de las cartas, es una figura textual que, eso sí, remite a una persona real. Y en este sentido las cartas de Lorca ofrecen tantos o más datos y conocimientos de sus destinatarios que del mismo autor: conocemos el apoyo de la familia, la preparación artística de Gasch, el respeto que irradiaba Juan Ramón Jiménez o la preparación literaria de Gerardo Diego.

El destinatario condiciona las dos llaves de la comunicación epistolar: el saludo inicial y la despedida, que en nuestro autor están caracterizados por su carácter coloquial y cariñoso. El saludo que predomina es «Querido o queridísimo (padres, amigos, Paquito, Melchorito...)» junto a la despedida «Abrazos y 
besos de vuestro hijo que os quiere", "Abrazos, abrazo cariñoso, un fuerte abrazo, un abrazo cordial», «mil besos de...». Las excepciones las constituyen los primeros contactos epistolares con destinatarios que el autor considera maestros, como es el caso de Juan Ramón Jiménez, quien le merecía mucho respeto:

Querido Juan Ramón:

Todos los amigos sevillanos y granadinos le saludan conmigo afectuosamente. [...]

Un expresivo saludo

(E.C.: 129-30).

Manuel de Falla (carta de junio de 1922, E.C.: 153-54):

Queridísimo don Manuel dos puntos [...] Un abrazo de su devotísimo y siempre amigo.

O a E. Marconi y Luigo Pirandello, que le invitan como representante español al Convegno Volta y García Lorca se excusa por no poder asistir (carta de septiembre de 1934, E.C.: 804-805):

Ilustrísimos señores: [...] con mi mayor sentimiento, acepten mis expresiones de agradecimiento y admiración.

Federico no olvida que su destinatario no es un ser aislado, de ahí que a los cariñosos saludos que le envía se unan los saludos a la familia, a los amigos, etc. Cuando se trata de un niño, usa frecuencia una fórmula característica «muchas cosas para» (por ejemplo Isabelita, su hermana menor), que denota gran cariño.

Este tono coloquial se potencia con un estilo aparentemente descuidado, fragmentario en ocasiones, que es propio de la carta privada y es el que da testimonio de su autenticidad. En Lorca la carta se vincula a la conversación con mucha frecuencia, de ahí la evocación constante del destinatario, las preguntas, las peticiones, el uso frecuente del diminutivo...: «Escríbeme en seguida», «Escríbeme!», «iQue me escribas!», «No me habéis escrito», «iEscríbeme y cuéntame cosas!», «¡Contéstame!», «Contesta!», «Que me escribas enseguida y largo», «QQue me escribáis mucho!», son formulas que se repiten y que muestran, con sus quejas, la necesidad por parte del emisor de que la comunicación se produzca, lo que equivale para él a tener noticias de su familia, saber la opinión crítica o la actividad artística de un amigo, etc. La desolación es siempre consecuencia de la falta de noticias, sea cual sea el carácter de éstas 
-privadas o literarias, artísticas-, si bien es cierto que ambos planos aparecen con frecuencia fundidos ya que el poeta, pintor o crítico suele ser además amigo; en el caso de la familia, su hermano Francisco desempeña también la labor de crítico, su madre, doña Vicenta, estímulo y apoyo del poeta desde su nacimiento, manifiesta igualmente un alto sentido crítico; además, el poeta pone al día a su familia de su actividad literaria ya que ellos no sólo la subvencionan, sino que pueden conocer sus proyectos, entusiasmos e ilusiones con una espontaneidad y cariño que podrían faltarle al crítico. Un ejemplo de la desesperación que puede invadir al poeta en sus deseos de establecer comunicación con su destinatario lo presenta una carta escrita a Salvador Dalí (verano de 1930, E.C.: 692-93):

Queridísimo amigo Salvador: ¿Cuánto tiempo hace que no nos vemos? Tengo ganas de hablar contigo. Y, además, me hace una falta enorme hablar contigo.

[...] Ardo en deseos de conocer cosas tuyas. Envíame fotos y cuéntame qué has hecho.

Quiero hablar contigo. He vivido demasiado incomunicado de tu amistad.

Dime qué piensas. Escríbeme algo.

Adiós. Siempre tuyo

Federico.

Por tanto, en el autor granadino se puede aplicar la afirmación de Patrizia Violi (ibidem: 90):

La dimensión comunicativa, que se presenta inmediatamente como uno de los rasgos más específicos de la escritura epistolar, se caracteriza no sólo por el reenvío a una situación interactiva externa al texto, sino sobre todo por las formas de su inscripción textual, en la modalidad específica de organización de la estructura discursiva.

$Y$ en lo que se refiere a la organización de la estructura discursiva fundamentalmente, el epistolario lorquiano presenta una gran variedad, lo que nos permite llevar a cabo una clasificación que, aunque no es en modo alguno exhaustiva ni responde a los cánones clásicos, nos da una idea de la variedad que presenta el género epistolar en nuestro autor; para ello pondremos algunos ejemplos de cada una de las variedades señaladas.

1. La epístola poética: a Sebastián Gasch, septiembre de 1927, E.C.: 51821; expone su poética, esto es, sus ideas sobre lo literario; ofrece, por 
tanto, un gran interés crítico. Este tipo de carta, en estado puro, es escasa, aunque las ideas poéticas de Federico aparecen dispersas por epístolas de diferentes tipos.

2. La epístola literaria: a Salvador Dalí, agosto de 1927, E.C.: 498-501; su lenguaje tiene una clara vocación literaria y no coloquial. No existen muchas cartas de esta clase.

3. Carta poema, en verso: a Néstor Martínez Fernández de la Torre, marzo de 1924, E.C.: 226-27, curiosa, posiblemente la única de este tipo. Hay que diferenciarla de la que le envía, por ejemplo, a Joaquín Romero Mureba en febrero de 1927, E.C.: 451 , donde le manda felicitaciones y un poema.

4. Epístola de carácter profesional: a Gerardo Diego, marzo de 1928, E.C.: 552-53, para pedirle colaboraciones para el gallo; a Le6n Sánchez Cuesta, 1933?, E.C: 751 , donde le pide que envíe un ejemplar del Libro de poemas al Centro Artístico de Granada.

5. Carta-saludo, postal: a Juan Gutiérrez Gili, agosto de 1927, E.C.: 512 13. Frecuentes en el Epistolario. Aunque son escuetas, presentan las relaciones de amistad de Federico con abundantes personas y su deseo de estar en contacto con ellas aunque fuera a través de un simple saludo, anticipo casi siempre de una carta más larga.

6. Carta de amor: a Salvador Dalí, agosto de 1927, E.C.: 511-12, donde San Sebastián, con su belleza, da pie a Federico a expresar su amor en un tono altamente poético con la ambigüedad derivada de su homosexualidad.

7. Carta a los amigos: es la más frecuente, en ella destacan todos los rasgos característicos de la epístola privada: intimidad, establecimiento de un pacto entre emisor y destinatario, etc.

8. Carta familiar, como las escritas desde Nueva York a su familia a raíz de la boda de su hermana con su amigo José Fernández Montesinos; el poeta no puede asistir a la boda pero se interesa hasta por los más mínimos detalles, aunque no deja de contar a su familia vivencias de ese momento y el desarrollo de su actividad literaria. En relación a estas cartas Anderson (en E.C.: 406) ha señalado que

su contenido está medido, retocado y a veces transformado, puesto que Lorca tiene una conciencia muy clara de cómo va a reaccionar la familia ante sus noticias y su manera de comunicarlas.

algo completamente l6gico, pues en este caso, como en los demás, el destinatario de la epístola ejerce una influencia previa a su escritura que no puede menos que reflejarse de una u otra forma. 
9. Carta-crónica, como algunas de las escritas desde Nueva York, Cuba y Argentina a su familia. En ellas García Lorca no sólo habla de sí mismo, sino de unos lugares y unas gentes que le sorprenden y fascinan, de unas costumbres nuevas, de una geografía y una arquitectura diferentes, del carácter de sus gentes: o cordial y bonachón e infantil y tonto (los norteamericanos) o acogedor y cariñoso en alto grado (los cubanos y argentinos).

10. Carta colectiva: escritas cuando Federico se encuentra con un grupo de colegas y amigos por algún motivo (viaje, tertulia...) y uno de ellos escribe a alguien, uniéndose el resto a la misiva. En este caso la intimidad desaparece para dar paso a la camaradería o a las anécdotas más o menos divertidas; son bastante frecuentes: a Ignacio Zuloaga, enero de 1922, E.C.: 139; a Emilia Llanos, noviembre de 1920, E.C.: 90-1; a Melchor Fernández Almagro, enero de 1923, E.C.: 170-71; a Manuel de Falla, noviembre de 1924, E.C.: 249-50; a Guerrero Ruiz, diciembre 1924, E.C.: 255-56; a José María de Cossío, marzo de 1927, E.C.: 456.

11. Cartas abiertas $o$ a instituciones: al Excmo. Ayuntamiento de Granada, diciembre de 1921, E.C.: 132-33; al Presidente del Centro Artístico de Granada, julio de 1927, E.C.: 490; a la Excma. Diputación Provincial de Granada, marzo de 1927, E.C.: 463-65; carta abierta a la redacción de La libertad, diciembre de 1927, E.C.: 536. En este apartado desaparece la intimidad ya que el objeto de las cartas son asuntos relativos a la actividad artística del poeta: petición de subvenciones, agradecimientos o puntualizaciones. No son muy abundantes.

12. Carta-manifiesto, colectiva: «A la colonia granadina de Madrid», marzo de 1925, E.C.: 266, 267; se comunica el homenaje a Ganivet y el acompañamiento de sus restos mortales. Escasas.

En suma, y para terminar, las epístolas de García Lorca constituyen hoy un material que ofrece abundante interés para el investigador en las direcciones más variadas: reconstrucción de la biografía, de la poética del autor, ambiente literario de la época..., pero, además, son una excelente muestra del género epistolar tal como se practicó durante la primera mitad del siglo XX en España $y$, por tanto, constituyen un valioso documento para reconstruir la teoría de la epístola privada, pues el resto de las manifestaciones son escasas en nuestro poeta, como se ha visto. 


\section{REFERENCIAS BIBLIOGRÁFICAS}

Ariess, PhillPPe y Duby, Georges, eds. (1990), Historia de la vida privada. Sociedad burguesa: aspectos concretos de la vida privada, Madrid, Taurus, tomo 8. (Traducción de Francisco Pérez Gutiérrez y Beatriz García).

CONCEJo, PIlar (1981), «El origen del ensayo hispánico y el género epistolar», Cuadernos Hispanoamericanos, 158-64.

GALLEGO MORELL, ANTONIO (1986), «Las cartas de Lorca y Lorca en sus cartas». En Andrés Soria Olmedo, ec., Lecciones sobre Federico García Lorca, Granada. Edición del Cincuentenario, 197-209.

Garcta LoRCA, Federico (1997), Epistolario completo, Madrid, Alianza, 1990. (Edición de Andrew A. Anderson y Christopher Maurer).

Garcia LorCa, Francisco (1980), Federico y su mundo, Madrid, Alianza, 1990. (Edición y Prólogo de Mario Hernández).

GiBson, IAN (1998), Vida, pasión y muerte de Federico Garcia Lorca (1898-1936), Madrid, Plaza y Janés.

GuILlÉn, Claudio (1991), «Al borde de la literariedad: literatura y epistolaridad», Tropelías. Revista de Teoría de la Literatura y Literatura Comparada 2, 71-92. Kany, Charles EmIL (1937), The Beginnings of the Epistolary Novel en France, Italy and Spain, Berkeley, University of California Press.

López Estrada, Francisco (1960), Antología de epístolas. Cartas selectas de los más famosos autores de la historia universal, Barcelona, Labor.

Pagés-RANGel, RoXanna (1997), Del dominio público: Itinerario de la carta privada, Amsterdam, Rodopi.

Roca SIERRA, Marcos (1990), «Retórica del discurso epistolar», Investigaciones Se mióticas III. Retórica y lenguajes, Madrid, UNED, II, 327-34.

SUÁREZ DE LA TORRE, EMIIlo (1987), «Ars epistólica. La preceptiva epistolográfica y sus relaciones con la retórica». En Gaspar Morocho Gayo, coord., Estudios de Drama y Retórica en Grecia y Roma, León, Universidad de León, 177-204.

Violi, PATRIzIa (1987), «La intimidad de la ausencia: formas de la estructura epistolar», Revista de Occidente 68, 87-99. 